\title{
An examination of environmental design parameters affecting walkable route choices in Cyprus
}

\author{
A. Savvides \\ University of Cyprus, Cyprus
}

\begin{abstract}
One of the characteristics of sustainable urban environments pertains to the extent to which the city fabric provides a variety of mobility alternatives in executing a specific journey. The extent to which this involves mechanized transport or alternatives that tax the human physique may have significant repercussions and offer tangible advantages to creating healthy urban environments. At the top of the list are means of mobility that force the city dweller to engage in physical cardiovascular activities, such as walking and/or bicycling. In the proposed paper conditions of existing urban design parameters as well as proposed corrections to physical formed are analyzed in terms of evaluating user comfort and route choices along a variety of urban pathways. The methodology of data collection and examination involves direct observation and mapping of route choices of city dwellers along the selected paths at three timeframes throughout the day and on characteristic days during the year. Specifically, the timeframes examined occur three times a day: during the early morning hours, at midday and later in the afternoon, during September, December, March and June in a given year (20142015). Along the selected route choices, environmental conditions affecting human comfort are also recorded, such as direct insolation or shading, ambient temperature, wind speed and humidity. The paper concludes with a discussion and recommendation of preferable environmental design parameters factoring in the design of urban walkable thoroughfares in Cyprus.
\end{abstract}

Keywords: urban design, environmental design, route choice, walkability. 


\section{Introduction}

In this current study, certain microclimatic parameters along a popular and well frequented urban passage way in Nicosia, Cyprus, exhibiting spatial conditions that result in shaded and insolated segments along that passage is being studied. User route choices along this passage way are observed against these microclimatic parameters with the aim of discerning correlation between urban morphology and microclimate on one hand and preferred user route choices on the other. Three specific parameters are being examined, namely: Air Temperature, Relative Humidity and Globe Temperature.

The current investigation is primarily quantitative in nature and examines the ways in which microclimatic conditions affect the thermal comfort and the behavior of urban dwellers as they utilize an active outdoors urban space. This approach accounts for about $50 \%$ of the fluctuations between the objective and subjective evaluation of user comfort in these active outdoors urban spaces. For a more holistic approach of such instances, it is recommended that the research teams engage in the investigation of aspects of the psychological adaptability of the users to the environment to which they are exposed. However, these aspects of psychological adaptability are hard to perceive from simple empirical observation methodologies.

A comprehensive examination of the state of the art with regards to the ways in which the perception of thermal comfort affects the way in which an outdoors space is being utilized or appropriated, includes references from researchers who have additionally incorporated not only environmental parameter records and empirical observations from the case study area, but they have also included extensive user questionnaires and debriefings.

\section{Literature review}

In the design of functional and evocative walkable routes in the contemporary city, it is important to revisit the lessons of the past and to consider the complexity of issues involved in user thermal comfort in outdoor urban spaces. The initial findings of the research being presented here seek to achieve a better understanding of the richness of microclimatic characteristics in outdoor urban spaces and the comfort implications for the people traversing them. These conditions influence people's behaviour and usage of outdoor walkable routes. In evaluating responses to their research questionnaire, Nikolopoulou et al. [1] note that awareness of the microclimate may be unconscious, but awareness may often result in a different use of urban space in different climatic conditions.

Improved microclimatic conditions have in turn major implications for the development of cities. By controlling sources of discomfort, sedentary activities, as well as the use of public transport, cycling and walking, are promoted, which are the goals of the public authorities engaged in envisioning alternative futures for thoroughfares such as Phaneromenis Square under study. Successful areas attract large numbers of people, which in turn attract businesses, workers, residents 
and the area becomes economically profitable. Moreover, successful thoroughfares may benefit the image of the city.

There is also adequate understanding of the influence of climate on urban settlements. For example, according to Nikolopoulou et al. [1], the way selfshading streets protect the buildings and the surrounding spaces from the hot sun, in hot arid climates or dispersed buildings and vegetation that allow for easy flow of wind through the spaces in hot humid climates, help create an appropriate architectural vocabulary by adapting it to the peculiarities of the local climate. In cases where the urban fabric is existent, such as the case of Phaneromenis Square, alterations are possible down to the scale of the urban block to exert microclimatic control. Shading whole streets is feasible whether in the form of trees, with the advantage of cooling via evapotranspiration through the leaves or man-made canopies with the available materials and appropriate, topical solutions.

Furthermore, a quantitative approach to the physical parameters has demonstrated that microclimatic parameters, indeed, strongly influence thermal sensations and these form the main focus of this investigation. However, the work of Nikolopoulou and Steemers [2] has thrown some light on the fact that psychological adaptation seems to become increasingly important as well. Although it was demonstrated that psychological adaptation is very important for the thermal evaluation of outdoor spaces and there is strong influence between the different parameters, it has been difficult to develop these speculations in more depth or to indicate more deterministic relationships to date and this body of work will not venture to develop that prong of investigation.

It is important to note, however, that appropriate microclimatic planning and careful design of urban spaces can provide protection from negative aspects and exposure to positive aspects of the climate, therefore, increasing the use of outdoor space throughout the year. Different seasons require different approaches, but a variety of spaces providing different environments would maximize both physical and psychological comfort. The physical environment and psychological adaptation has been argued by Nikolopoulou and Steemers [2] to be complementary rather than contradictory and consideration of this duality could increase the use of a city's open spaces, strengthening social interaction between users by allowing opportunities for such interaction to take place.

Picot also shows that vegetation should be considered as a real tool for the control of microclimatic conditions in external spaces [3]. In the present case study, this becomes a reality when trees reach their adult dimensions and are considered in alternative layouts along Phaneromenis Square. The screening potential of the tree foliage with the direct effect of reducing the solar radiation absorbed by a typical person situated below a tree canopy is considerable. Trees absorb and reflect the biggest part of the solar radiation and the data obtained shows that vegetation should be seen as an active element, reflecting energy that can increase the terrestrial radiation absorbed by a person. The use of vegetation as a tool in microclimatic control therefore needs to take into account the shading performance evolution of vegetation and eventually provide temporary and complementary screening solutions. These can be included in projects in various ways, such as, urban furniture, seasonal fabric screens and/or artificial canopies 
with the aim of providing shade. These parameters need to be further studied even if empirical experiences show that various greening initiatives located in a neighborhood of the buildings can modify the relationship with their environment and the sensations of the users.

Although not verified in this study patterns discussed before by Ali-Toudert and Mayer [4] give some information about the most suitable locations of trees within the street to improve its comfort level and this has been taken into account in the simulations in this body of work. In all cases, tree plantings in streets of about $\mathrm{H} / \mathrm{W} 1 / 40.5$ ratios have been shown to be suitable, while for higher aspect ratios, the overheated E-W streets are likely the ones where the implementation of vegetation is most desirable because the discomfort duration is long. Trees would preferably be located on the south-facing side or in the central part of the street, depending on the aspect ratio and street use.

Another consideration by Ali-Toudert and Mayer [4] is the use of materials with high thermal capacities, which would help reduce the long-wave radiation fluxes from the surrounding surfaces in the daytime and consequently decrease perceived higher temperatures.

Regarding the wind, there is increasing discomfort as wind speed increases, depending on air temperature, as at high air temperatures the cooling effect of the wind is desired. According to Nikolopoulou and Lykoudis and in relation to user comfort [5], the majority of the people found outside have reported feeling comfortable, exceeding $75 \%$ for all cities on a yearly basis. Sources of discomfort include strong wind at northern climates and stale conditions for air temperatures over $30^{\circ} \mathrm{C}$. Regarding humidity, people are not very good at judging changes in humidity levels, unless relative humidity is very high or very low and normally in conjunction with temperature conditions, indicating a significant second role for relative humidity in the overall comfort sensation.

Again, according to Nikolopoulou and Lykoudis [5], investigating the temperatures where people feel neither warm nor cool, showed a great variation across Europe of over $10^{\circ} \mathrm{C}$, just below, $23^{\circ} \mathrm{C}$ for Athens, in Greece (which forms an approximate datum for the current analysis) and $13{ }^{\circ} \mathrm{C}$ for Fribourg, in Germany. Transitional seasons have wider neutrality zones for southern cities, such as Nicosia, yet this difference is minimized for northern cities in Germany, for example. For the purposes of this study this could be attributed to the difference in behavior between the southern and the northern cities, a result of experience to a different range of climatic conditions and difference in sensitivity to heat and cold.

\section{Methodology of investigation}

The case study used is along the Phaneromenis Church passageway adjacent to the public square by the same name - with corroborating studies at two more linear passageways in Larnaca and Limassol - all being frequently used shortcuts within the historic cores of their respective cities. The base case study in Phaneromeni is organized along west-northwest/east-southeast axis and it is fully pedestrianized. The adjoining buildings cause stripes of shaded area along the passageway at 
different times and by different percentages of the total area throughout the day (figure 1). The building masses primarily affecting this state of affairs are located along the southern border, while building masses along the northern border, as well as a row of trees, are responsible for partial shading at certain times of the season.

It is along this passageway that a grid was laid down comprised of six points of reference as prescribed by Oratiou [6] and Mazeri [7] and it was used to monitor microclimatic parameters every 10 minutes and record values for Air Temperature, Relative Humidity, Globe (sphere) Temperature (figures 2, 3, 4 and 5 ) and supporting values for wind direction that were subsequently used in the discussion regarding Relative Humidity and its effect on user comfort of this outdoor site. The grid was laid down in such a way so that the data gathered would cover all possible route choices that the users of this passageway may have taken with regards to shaded and insolated parts of the space.

The spatial and environmental design parameters were recorded using a digital camera, while the microclimatic conditions were executed using a Heat Shield device. This is a compact mobile meteo station that allows the recoding of the air temperature, the natural wet bulb temperature, the globe temperature (using a $5 \mathrm{~cm}$ globe and sensor) and the relative humidity. The device was located at $120 \mathrm{~cm}$ above ground level and the recording sessions were kept within a 10-minute span. In addition, weather data were also collected by two additional fixed meteo stations - located at 5 , and $9 \mathrm{~m}$ respectively above ground in the general vicinity taking readings for relative humidity and air speed. However, the comparison between the recordings from the mobile station and the fixed stations proved to be unreliable and they have not been accounted in the quantitative analysis that follows. These recordings are just treated as additional representative values from the broader case study area and any inferences made are qualitative rather than quantitative.

These are then juxtaposed against the percentage from the total number of users that make the choice to walk in the shaded part of this passage way versus the insolated part of the passageway. Measurements are taken at three distinct times of the day: morning (09:00); noon (12:00); and afternoon (15:00), during typical days of the Winter (W), Spring/Fall (S/F) and Summer (S) periods with no cloud cover.

\section{Discussion of results}

The mean temperatures recorded at Phaneromeni Square using the compact mobile meteo station during the winter, spring/fall and summer periods were $19.8^{\circ} \mathrm{C}$, $29.4^{\circ} \mathrm{C}$ and $33.8^{\circ} \mathrm{C}$ respectively. The lowest value was recorded in the morning hours of the winter period at $19.4^{\circ} \mathrm{C}$, while the highest value was recorded during the afternoon hours of the summer period at $36.4^{\circ} \mathrm{C}$.

Relative humidity recordings presented comparatively higher values during the morning periods in all seasons, while there was no significant difference in the values recorded during the noon and afternoon periods. The lowest mean relative 

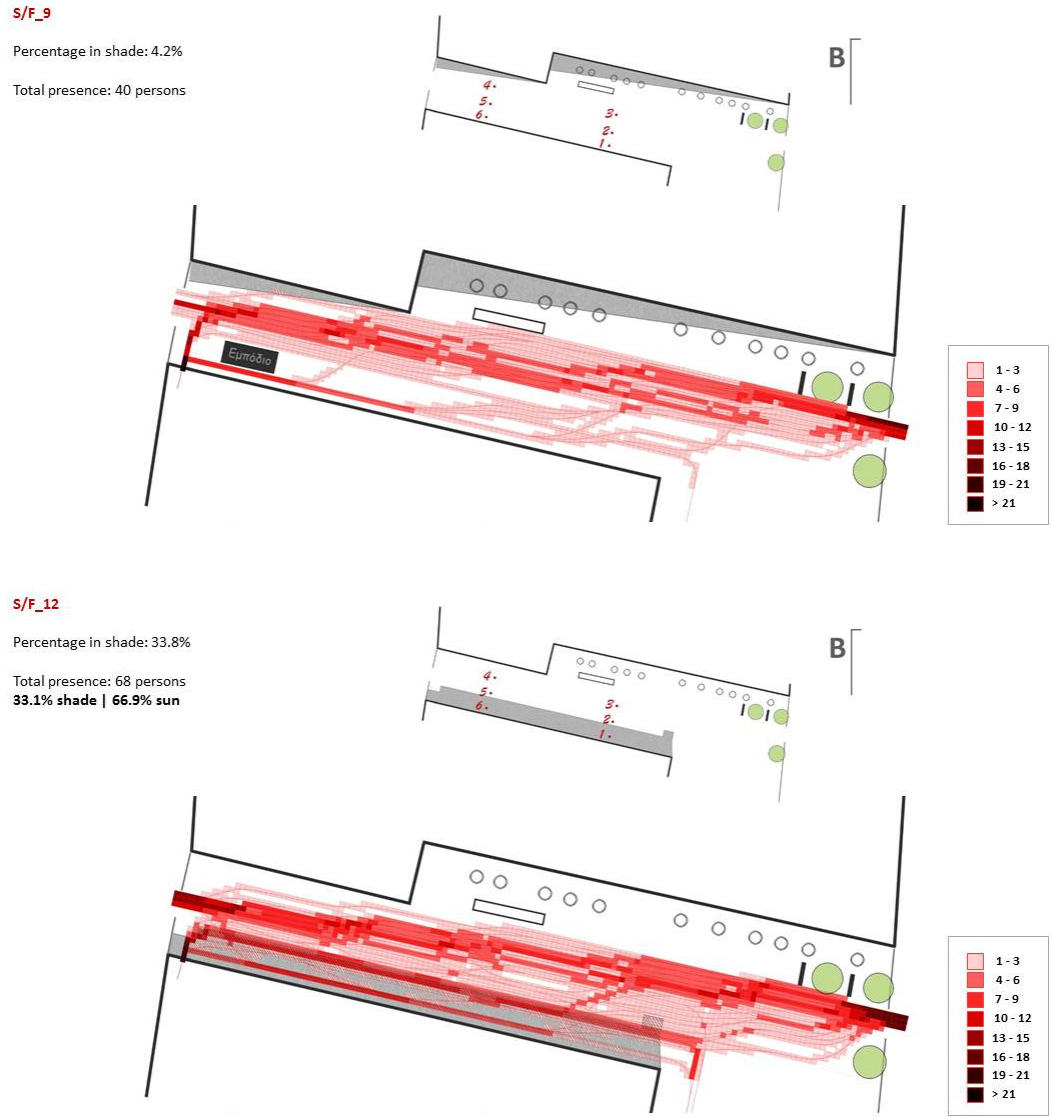

\section{S/F_15}

Percentage in shade: $51.1 \%$

Total presence: 47 persons $64.9 \%$ shade | $35.1 \%$ sun
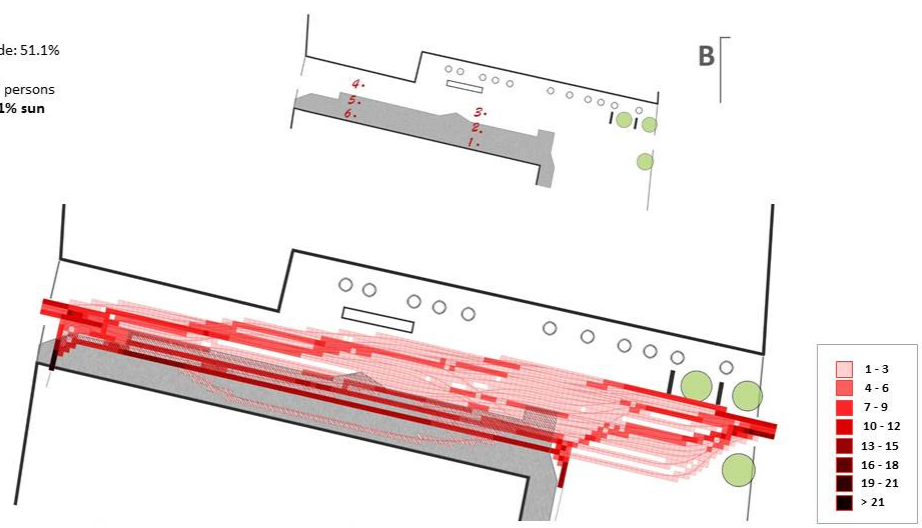

Figure 1: User route choices along Pheneromenis. 


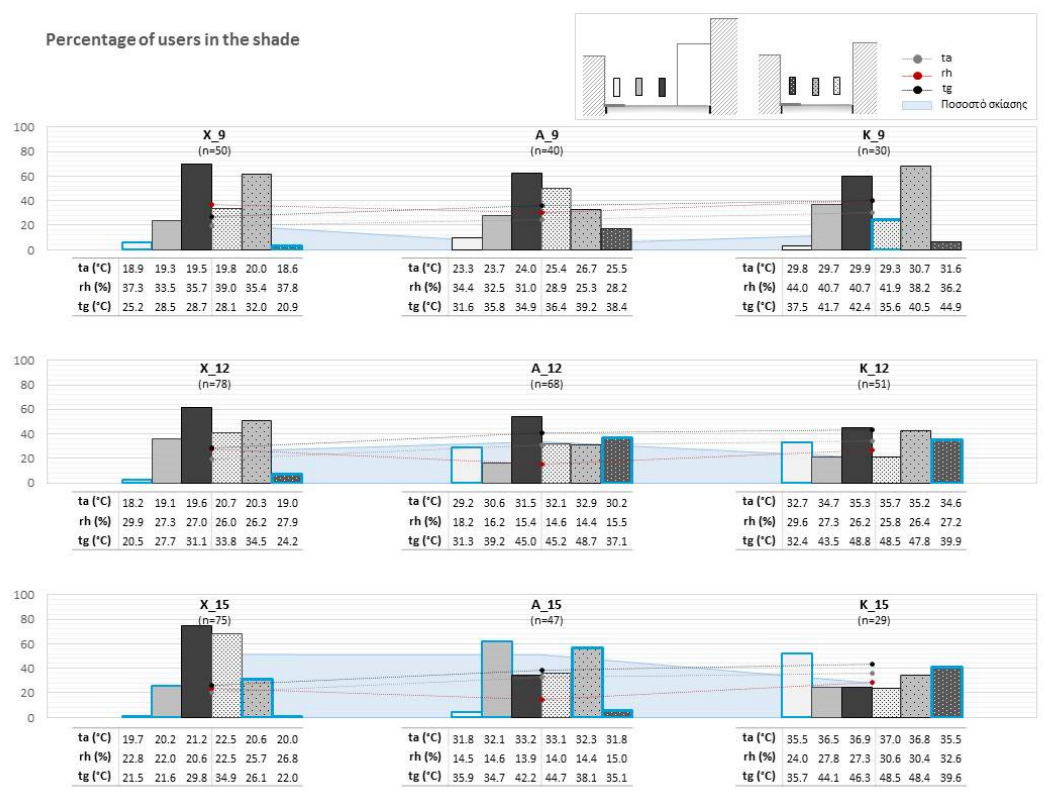

Figure 2: Percentage of users in the shaded part of the passage.

\section{Percentage of users in the shade}

Users in the shade (\%) - Air temperature $\left({ }^{\circ} \mathrm{C}\right)$

W|S/FIS_09:00

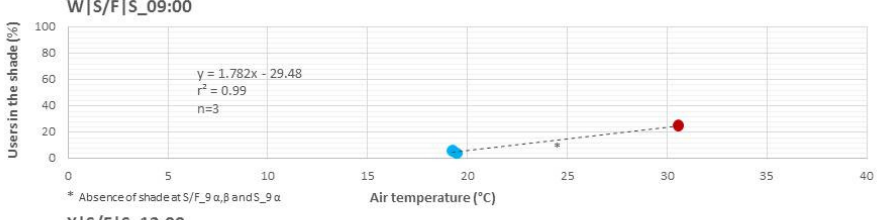

$\mathrm{X}|\mathrm{S} / \mathrm{F}| \mathrm{S} \_12: 00$

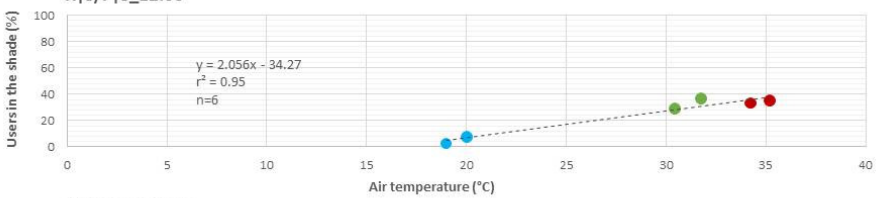

W|S/F $\mid$ S_15:00

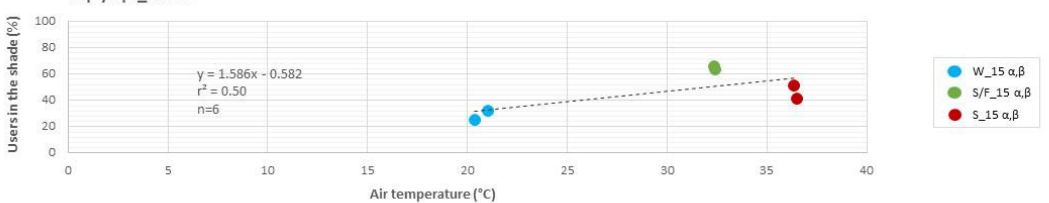

Figure 3: Effect of air temperature on percentage of users in the passage. 


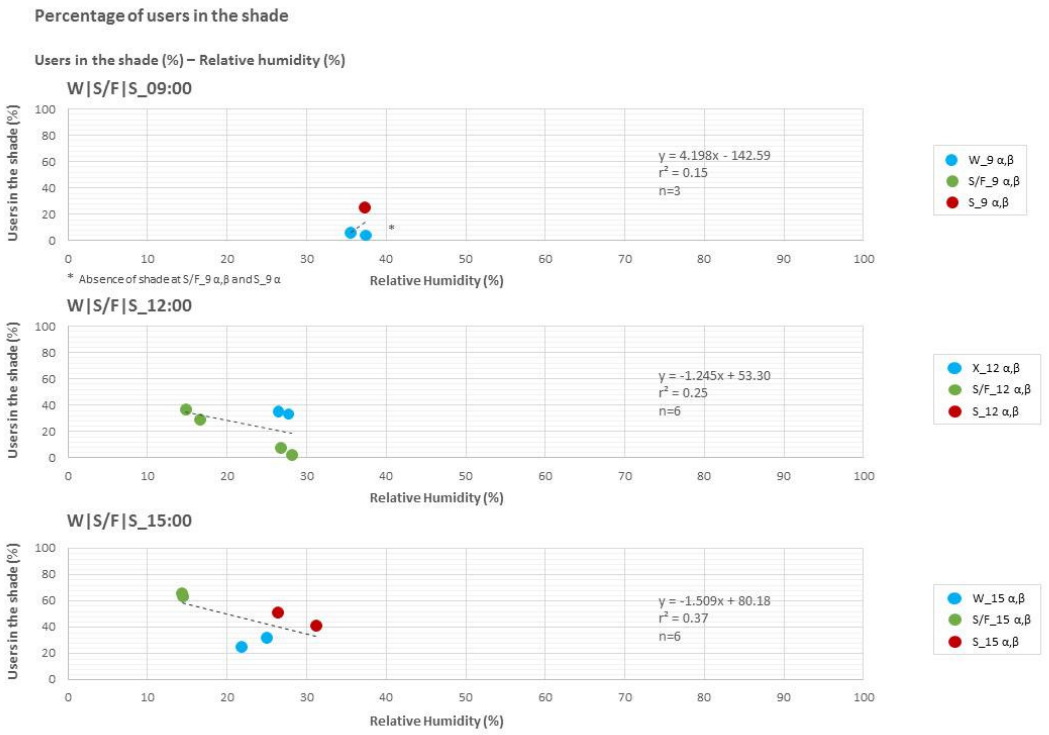

Figure 4: Effect of relative humidity on percentage of users in the passage.

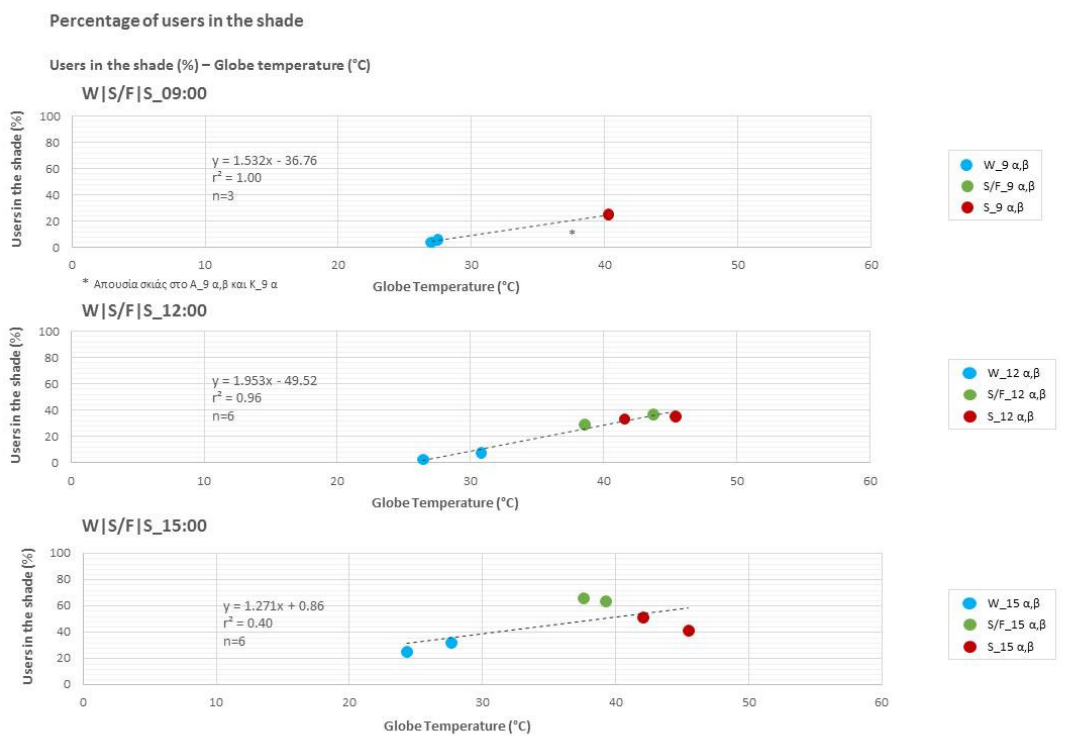

Figure 5: Effect of globe (sphere) temperature on percentage of users in the passage. 
humidity value was $14.4 \%$ (spring at 15:00), while the highest value was $40.3 \%$ (summer at 09:00). In the winter, the spring and the summer the mean values for relative humidity recorded were $29.1 \%, 20.0 \%$ and $32.1 \%$ respectively.

In comparing the mean values for the globe (sphere) temperature per period, a rise of these values is noted when there is a rise in air temperature $(\mathrm{r} 2=.92)$. A slight decrease in the mean values is noted during the afternoon winter and spring periods as a result of a greater number out of the six reference points that are to be found in the shade. The lowest mean value recorded was $26^{\circ} \mathrm{C}$ (winter at 15:00) and the highest was $43.8^{\circ} \mathrm{C}$ (summer at 15:00). In the winter period the mean globe temperature was $27.3^{\circ} \mathrm{C}$, in the summer it was $38.5^{\circ} \mathrm{C}$ and in the summer it was 42. $6^{\circ} \mathrm{C}$.

The air temperature recorded at the six reference points in the site under investigation takes on different values depending on whether each reference point is insolated or shaded. For every season considered, the reference points which are shaded record lower values, which is to be expected. In the winter the smallest air temperature difference between the six reference points was $0.6^{\circ} \mathrm{C}$ at 09:00 and the greatest was $2.5^{\circ} \mathrm{C}$ at $15: 00$. In the spring the smallest air temperature difference was $1.3^{\circ} \mathrm{C}$ at $15: 00$ and the greatest $2.7^{\circ} \mathrm{C}$ at $12: 00$. In the summer, the smallest and greatest air temperature differences were $1.1^{\circ} \mathrm{C}$ and $2.6^{\circ} \mathrm{C}$ respectively, both of them recorded at noontime.

Small differences in the relative humidity recordings are probably the result of the slight time differences between recording the values from the six reference stations (it takes 30 minutes to record the values from the six reference points). The smallest difference recorded was $0.7 \%$ in the spring at 15:00 and the greatest $5.7 \%$ in the summer at 09:00.

With regards to the recording for the globe (sphere) temperature, the differences amongst the values recorded vary significantly depending on whether the reference points were insolated or shaded at the time of the measurements. These differences show slight rises in values during subsequent periods from winter to summer. More specifically the smallest and greatest differences in the values recorded in the winter, the spring and the summer periods were: $3.5^{\circ} \mathrm{C}$ at $09: 00$ and $12.9^{\circ} \mathrm{C}$ at $\left.15: 00\right) ; 7.5^{\circ} \mathrm{C}$ at $15: 00$ and $13.7^{\circ} \mathrm{C}$ at $12: 00$; and $8.6^{\circ} \mathrm{C}$ at $12: 00$ and $16.4^{\circ} \mathrm{C}$ at $12: 00$, respectively.

\section{Conclusions}

Certain conclusions may be drawn when the recordings above that examined the mean values of the microclimatic parameters recorded per seasonal period (winter, spring and summer) and at specific timeframes (morning, noon and afternoon) are juxtaposed to on site observations in the number of people that have frequented and traversed the site on foot or by bicycle throughout the entire duration of this study.

The rise in air temperature results in a decrease in the total presence of users in the Paneromenis Square site throughout all three seasonal periods and timeframes when the values from the six reference points were recorded. The linear relationships that were recorded between the two variables indicated a strong 
correlation. The afternoon timeframe recordings indicate the greatest reduction in the number of users traversing the site, while during the two other timeframes the percentage reduction in the number of users in comparable. During the morning and noon timeframes the reduction in the number of users is 18 and 16 persons respectively, as the air temperature rises by $10^{\circ} \mathrm{C}(\mathrm{r} 2=1.00$ and $\mathrm{r} 2=0.82)$, while in the afternoon timeframe the number of users is reduced by 28 people $(\mathrm{r} 2=0.98)$.

The relationships recorded for the values with regards to relative humidity and its effect of users traversing the site were insignificant for all three timeframes considered with respective indicators at $\mathrm{r} 2=0.14$ (morning), $\mathrm{r} 2=0.02$ (noon) and $\mathrm{r} 2=0.06$ (afternoon). The globe (sphere) temperature indicates a strong negative correlation with regards to the presence of users traversing the site. The rise of the mean value by $10^{\circ} \mathrm{C}$, results in a decrease in the number of users traversing the site by 15 persons during the morning and noon timeframes resulting in statistical indicators of $\mathrm{r} 2=0.96$ and $\mathrm{r} 2=0.75$ respectively. An even greater reduction in the number of users traversing the site was recorded for the afternoon timeframe, resulting in 25 fewer users for a statistical indicator of $\mathrm{r} 2=0.99$.

Based on an examination of the microclimatic parameters affecting users traversing Phaneromenis Square, the reference points in the shade recorded lower values for air temperature and globe temperature compared to reference points that were insolated, which was as expected. The conclusions drawn below are in reference to the examination of the relationship between these microclimatic parameters and the percentage of users that chose to walk in the shade and which was partially estimated by dividing the percentage of the people traversing the site who chose to do so in the shade by the percentage of the area of the square which is shaded at that a given timeframe. These observations were further substantiated by further examining the flow passage diagrams of all the users observed traversing the site in question during all the seasonal periods at the three timeframes mentioned.

The air temperature is strongly positively correlated with the percentage presence of users in the shaded parts of the square during the morning and noon timeframes. During the afternoon a similar correlation with the percentage presence of users was not so strong. On the contrary the correlation between air temperature and a desire to be in the shade was strongly positive throughout all three timeframes of investigation. A rise in air temperature by $10^{\circ} \mathrm{C}$ causes a rise in the percentage of people who chose to walk in the shade by $18 \%$ with a statistical indicator of $\mathrm{r} 2=0.99$ for the morning timeframe and by $21 \%$ with a statistical indicator of $\mathrm{r} 2=0.95$ during the noon timeframe. Moreover, a rise is noted in the desire of people to be in the shade in the morning (by 1.52 with a statistical indicator of $\mathrm{r} 2=1.00$ ), compared to the noon timeframe (by 1 with a statistical indicator of $\mathrm{r} 2=0.93$ ) and the afternoon timeframe (by 0.68 with a statistical indicator of $\mathrm{r} 2=0.93$ ). On the other hand, relative humidity had a very slight or even negligible correlation to the percentage presence of people in the shade or their desire to be in the shade.

Lastly, a rise in globe (sphere) temperature results in a rise in the percentage of users in the shade during the morning and noon timeframes. In the morning a rise in globe temperature by $10^{\circ} \mathrm{C}$ results in a rise to the percentage of people in the 
shade by $15 \%$ with a statistical indicator of $\mathrm{r} 2=1.00$, while at noon this value is at $20 \%$ with a statistical indicator of $\mathrm{r} 2=0.96$. In the afternoon timeframe a similar correlation with the percentage presence of users was not strong. With regards to a correlation between globe temperature and a desire of users to be in the shade, the observed relationship is strong for all three timeframes with indicative values, when the globe temperature rises by $10^{\circ} \mathrm{C}$, of: $1.31,0.82$ and 0.58 during the morning $(\mathrm{r} 2=1.00)$, noon $(\mathrm{r} 2=0.86)$ and afternoon $(\mathrm{r} 2=0.86)$ timeframes, respectively.

These conclusions may then be directly translated to urban design tools with which one my influence the use and appropriation of urban passages depending on the conditions of user comfort or discomfort one may wish to create.

\section{References}

[1] Nikolopoulou, M., Baker, N. and Steemers, K. (2001) Thermal comfort in outdoor urban spaces: understanding the human parameter. Solar Energy, Vol. 70, No. 3, pp. 227-235.

[2] Nikolopoulou, M. and Steemers, K. (2003) Thermal comfort and psychological adaptation as a guide for designing urban spaces. Energy and Buildings, Vol. 35, pp. 95-101.

[3] Picot, X. (2004) Thermal comfort in urban spaces: impact of vegetation growth - Case study: Piazza della Scienza, Milan, Italy. Energy and Buildings, Vol. 36, pp. 329-334.

[4] Ali-Toudert, F. and Mayer, H. (2006) Numerical study on the effects of aspect ratio and orientation of an urban street canyon on outdoor thermal comfort in hot and dry climate. Building and Environment, Vol. 41, pp. 94-108.

[5] Nikolopoulou, M. and Lykoudis, S. (2006) Thermal comfort in outdoor urban spaces: Analysis across different European countries. Building and Environment, Vol. 41, pp. 1455-1470.

[6] Oratiou, M. (2013) Thermal behavior of paving materials in open spaces. Master's Thesis, University of Cyprus, Department of Architecture.

[7] Mazeri, G. (2015) The role of thermal comfort in increasing physical activity in open public spaces. Master's Thesis, University of Cyprus, Department of Architecture. 